\title{
Mutant p53 tunes the NRF2-dependent antioxidant response to support survival of cancer cells
}

\author{
Kamil Lisek ${ }^{1,4}$, Elena Campaner ${ }^{1,2}$, Yari Ciani ${ }^{1}$, Dawid Walerych ${ }^{1,3}$ and Giannino Del \\ Sal ${ }^{1,2}$ \\ ${ }^{1}$ National Laboratory CIB, Area Science Park Padriciano, Trieste 34149, Italy \\ ${ }^{2}$ Department of Life Sciences, University of Trieste, Trieste 34127, Italy \\ ${ }^{3}$ Mossakowski Medical Research Centre, Polish Academy of Sciences, Warsaw 02-106, Poland \\ ${ }^{4}$ Present address: Max-Delbrück-Centrum for Molecular Medicine, Berlin 13092, Germany \\ Correspondence to: Giannino Del Sal, email: gdelsal@units.it \\ Dawid Walerych, email: dwalerych@imdik.pan.pl \\ Keywords: NRF2; mutant p53; cancer; oxidative stress \\ Received: August 20,2017 Accepted: March 09, $2018 \quad$ Published: April 17, 2018 \\ Copyright: Lisek et al. This is an open-access article distributed under the terms of the Creative Commons Attribution License 3.0 \\ (CC BY 3.0), which permits unrestricted use, distribution, and reproduction in any medium, provided the original author and source \\ are credited.
}

\section{ABSTRACT}

NRF2 (NFE2L2) is one of the main regulators of the antioxidant response of the cell. Here we show that in cancer cells NRF2 targets are selectively upregulated or repressed through a mutant p53-dependent mechanism. Mechanistically, mutant p53 interacts with NRF2, increases its nuclear presence and resides with NRF2 on selected ARE containing gene promoters activating the transcription of a specific set of genes while leading to the transcriptional repression of others. We show that thioredoxin (TXN) is a mutant p53-activated NRF2 target with pro-survival and pro-migratory functions in breast cancer cells under oxidative stress, while heme oxygenase 1 (HMOX1) is a mutant p53-repressed target displaying opposite effects. A gene signature of NRF2 targets activated by mutant p53 shows a significant association with bad overall prognosis and with mutant p53 status in breast cancer patients. Concomitant inhibition of thioredoxin system with Auranofin and of mutant p53 with APR-246 synergizes in killing cancer cells expressing p53 gain-of-function mutants.

\section{INTRODUCTION}

The transcription factor nuclear factor erythroid 2-related factor 2 (NRF2) is the main and evolutionary conserved regulator of the antioxidant pathways in the cell. In response to oxidative stress, the inhibitor Keap1 cannot degrade NRF2, and newly synthesized NRF2 accumulates, translocates to the nucleus and drives the transcription of ARE containing genes [1]. The role of the NRF2-Keap1 pathway in cancer initiation, progression and chemoresistance has been studied extensively in the recent years. Keap1 mutations activating NRF2 or mutations in NRF2 gene itself are frequent events in many cancer types $[2,3]$. Moreover, various oncogenes have been reported to impact the NRF2 pathway by upregulating total mRNA and protein levels of NRF2 $[4,5]$. NRF2 controls key components of endogenous antioxidant systems in both cancer and normal cells $[1,6]$. Until now over 500 genes have been reported to be under NRF2 control [7]. While in normal cells the NRF2/Keap1 antioxidant pathway plays a crucial role in maintaining cellular homeostasis and preventing tumorigenesis [1], in cancer cells high expression of NRF2-regulated genes provides them with cytoprotection, contributing to their oncogenic capabilities $[8,9]$.

Mounting evidence links the oncogenic activities of mutant p53 [10] to different aspects of NRF2 transcriptional activity [11] although reported results open a number of questions on the interplay between these two factors, as mutant p53 was shown to repress the elements of the NRF2-dependent oxidative stress response [12], while other researchers showed that 
mutant p53 activates NRF2 gene transcription [13]. We have previously demonstrated that while in cancer cells mutant p53 activates proteasome genes in cooperation with NRF2, it indeed simultaneously represses another NRF2 target gene - heme oxygenase 1 (HMOX1) [14]. The physiological significance of this mutant p53-dependent bi-directional NRF2 target regulation in cancer cells has remained unclear.

Here, we investigate how mutant p53 impacts on NRF2 activity acting as a molecular switch that turns onor off- specific components of the NRF2 transcriptional program thus tuning NRF2 activity in cancer cells. We also provide evidence that simultaneous targeting of mutant p53 and of the thioredoxin system by combining APR246/PRIMA-1MET and Auranofin, synergizes providing a therapeutic advantage against breast cancer cells.

\section{RESULTS}

\section{Mutant p53 differentially regulates NRF2 transcriptional targets}

In order to evaluate the impact of mutant p53 on the expression of NRF2 transcriptional program, we perused already available datasets to sort out a signature consisting of well established NRF2 target genes which represent various biological processes important for normal and cancer cell metabolism. We selected key NRF2 downstream targets regulating the antioxidant systems of the cell, such as glutathione ( GCLC, GCLM), thioredoxin (TXN, TXNRD1), as well as genes encoding for: cystine antiporter (SLC7A11), quinone oxidoreductase (NQO1), heme oxygenase 1 (HMOX1), multidrug resistance proteins ( $A B C C 3, A B C C 5$ ), proteasome subunits (PSMA2, $P S M C 1, P S M D 10)$ and phosphoserine aminotransferase (PSAT1) [7, 15-17].

In order to understand to what extent the NRF2 transcriptional profile differs between normal and cancer cells of the breast epithelium, we compared MDAMB-231 (a breast cancer cell line bearing missense mutant p53), MCF7 (a breast cancer cell line harboring wild-type p53) and MCF10A (untransformed, immortalized breast epithelial cells) for basal expression of the NRF2 gene signature (Figure 1A). Breast cancer cells (MDA-MB-231 and MCF7) showed a markedly higher expression of NRF2 and of all investigated NRF2 targets than normal cells (MCF10A), confirming previous observations from other cellular models $[5,18,19]$.

We expected from our previous study that mutant p53 may differentially affect subsets of NRF2 targets [14]. Hence, we compared the expression of selected NRF2 target genes between normal breast epithelial MCF10A cells bearing wild-type p53 (wtp53), MCF10A cells silenced for TP53 $\left(\mathrm{MCF} 10 \mathrm{~A}^{+ \text {shTP53 }}\right)$ and MCF10A cells silenced for wild-type TP53, ectopically overexpressing the oncogenic mutant p53 (mtp53) R280K (MCF10A $\left.{ }^{+m_{t p} 53280 K}\right)$. In this experimental setup we observed that in the presence of mutant p53 only a subset of the NRF2 transcriptional program is upregulated, while other NRF2 targets are repressed. MCF10A ${ }^{+m t p 53 \mathrm{R} 280 \mathrm{~K}}$ expressed higher levels of a proteasome subunit gene (PSMC1), of thioredoxin system genes (TXN, TXNRD1), and of glutathione (GCLM) in comparison to normal MCF10A cells, while the expression of targets such as $H M O X 1, S L C 7 A 11, A B C C 3$ was repressed in the presence of the mutant p53 gain of function (GOF) variant (Figure 1B).

Interestingly, in MCF10A cells stably expressing the oncogenic variant of HRAS (MCF10A ${ }^{+H R A S}$ ), expression of all investigated NRF2 targets was significantly upregulated, confirming previous reports in different cellular systems indicating that other oncogenes (i.e. oncogenic alleles of $K R A S, H R A S, B R A F$ or $C M Y C$ ) have an overall activating effect on the NRF2 transcriptional activity [5] (Figure 1B).

We confirmed the differential regulation of NRF2 transcriptional targets by mutant p53 also in MDAMB-231 breast cancer cells in which we silenced mutant TP53 expression with siRNAs $[14,20]$. In this context, we observed a downregulation of PSMC1, TXN, TXNRD1, and GCLM, and an upregulation of $H M O X 1, S L C 7 A 11$ and $A B C C 3$ transcription (Figure $1 \mathrm{C}$ and Supplementary Figure 1A). Similarly, in p53-null H1299 lung cancer cells upon stable introduction of mutant p53 variant $\mathrm{R} 175 \mathrm{H}$, we observed an upregulation of $T X N$ and TXNRD1 and a concomitant downregulation of $H M O X 1$ and $A B C C 3$ transcription (Supplementary Figure 1B). Silencing of $N R F 2$ abolished mutant p53 ability to sustain $T X N$ and TXNRD1 mRNA levels indicating that mutant $\mathrm{p} 53$ requires NRF2 to promote the transcription of these genes.

Since NRF2 plays a major role as an antioxidant response regulator in cancer and in normal cells we sought to test if the regulation of the expression of NRF2 targets by mutant p53 is maintained also under the oxidative stress conditions. We first tested different oxidative stress inducers in promoting NRF2 activation in MDAMB-231 cells by analyzing both NRF2 localization and the expression levels of its targets. As shown in Supplementary Figure 2A, 2B, $\mathrm{H}_{2} \mathrm{O}_{2}$, menadione and sodium arsenite induced NRF2 nuclear localization and transcription of its targets in a similar manner. Considering the reported toxic effect of menadione and sodium arsenite [21-24], we selected $\mathrm{H}_{2} \mathrm{O}_{2}$ as oxidative stress inducer for the next experiments. We then treated $\mathrm{MCF} 10 \mathrm{~A}^{+}$ RAS, MCF10A ${ }^{+m t p 53}$ R280K or MDA-MB-231 cells with $\mathrm{H}_{2} \mathrm{O}_{2}$ and observed that NRF2 targets and NRF2 itself are transcriptionally activated in response to exogenous oxidative stress stimuli and that mutant p53 regulates NRF2 targets in a similar way as in unstressed conditions (Figure 1D and Supplementary Figure 2C, 2D). Abrogating the expression of NRF2 with siRNA inhibits NRF2 target expression in both normal and oxidative stress conditions (Figure 1C, 1D and Supplementary Figure 2C, 2D). 
Next, we validated the effect of mutant p53 on NRF2 transcriptional program performing rescue experiments in MDA-MB-231 cells in which we stably silenced mutant TP53 (MDA-MB-231 ${ }^{\text {sh } T P 53}$ ). We investigated $T X N$ as a representative of NRF2 targets activated by mutant p53, and $H M O X 1$ among NRF2 targets repressed by mutant p53. In this setup, we observed downregulation (at both mRNA and protein levels) of $T X N$, and upregulation of the mRNA level of HMOX1 (Figure 1E and Supplementary Figure 2E). Reintroducing HA-tagged mutant p53 in these cells (MDA-

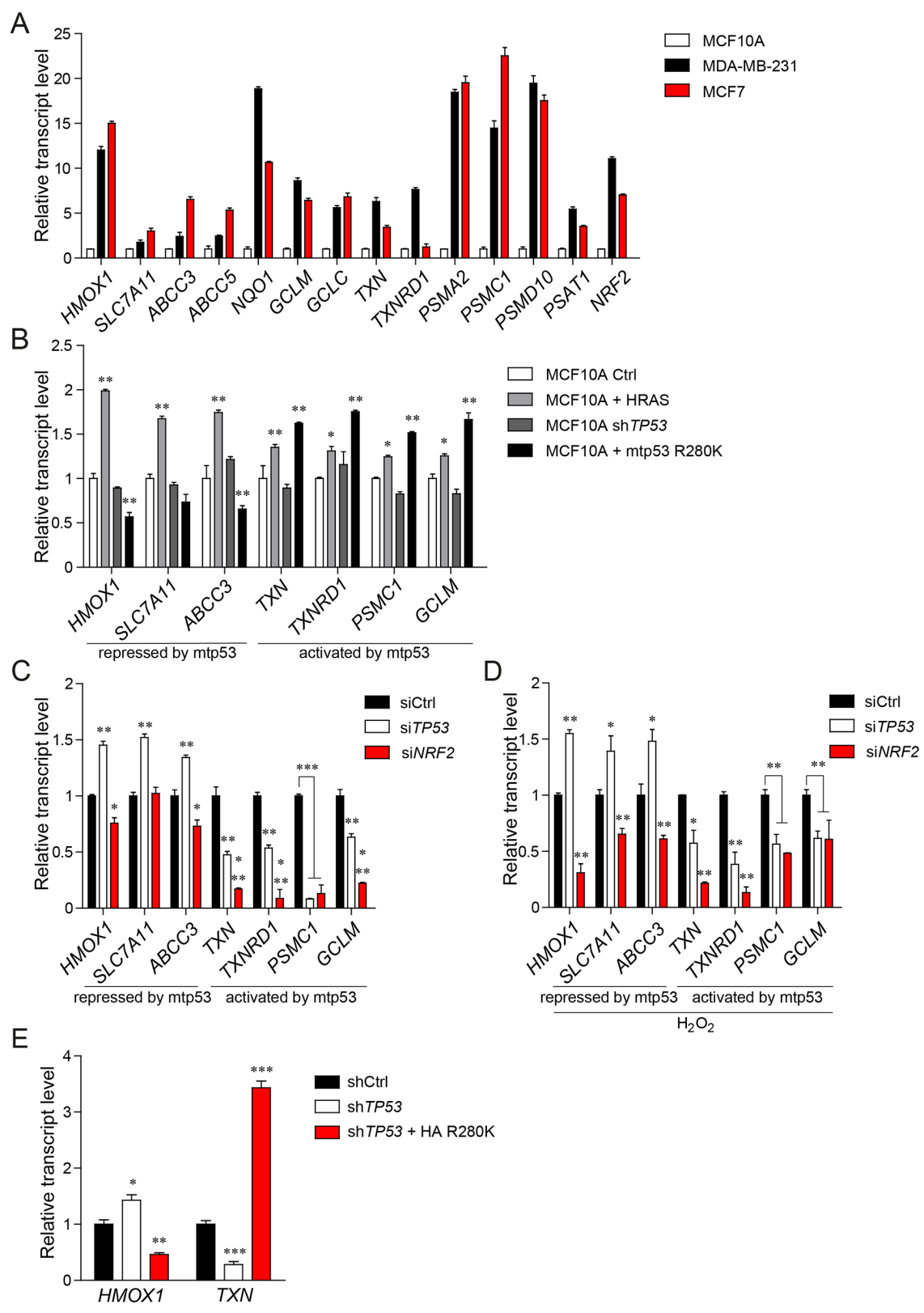

Figure 1: Mutant p53 differentially regulates the expression of NRF2 transcriptional targets. (A) Expression of selected NRF2 targets in breast cancer cell line MDA-MB-231 (bearing mutant p53 R280K), breast cancer cell line MCF7 (bearing wt p53) in comparison with normal epithelial breast cell line MCF10A (bearing wt p53). (B) Expression of NRF2 targets in MCF10A cells. Normal epithelial cells (MCF10A) stably transfected with empty retroviral vector (Ctrl), vector encoding oncogenic variant H-Ras G12V (HRAS), vector encoding shRNA targeting TP53 transcript (shTP53), and mutant p53 CDS shRNA-resistant HA-tagged variant R280K, stably introduced into the MCF10A shTP53 cell line (+mtp53 R280K). (C,D) Effect of mutant TP53 or NRF2 silencing on the selected NRF2 targets in MDA-MB-231 cells in unstressed conditions (C) or under oxidative stress induced by incubation of MDA-MB-231 cells with $500 \mu \mathrm{M} \mathrm{H}_{2} \mathrm{O}_{2}$ for 12 hours (D). (E) Expression levels of HMOX1 and TXN in MDA-MB-231 cells stably silenced for control (shCtrl), TP53 (shTP53), or TP53 together with stable mutant p53 R280K overexpression (shTP53 + HA R280K). Data shown in A-E are the means \pm s.d. of $\mathrm{n}=3$ independent experiments, ANOVA test with Bonferroni correction: ${ }^{*} \mathrm{p}<0.05,{ }^{* *} \mathrm{p}<0.01,{ }^{* * *} \mathrm{p}<0.001$. Expression levels are given relative to $A C T B$. 
A
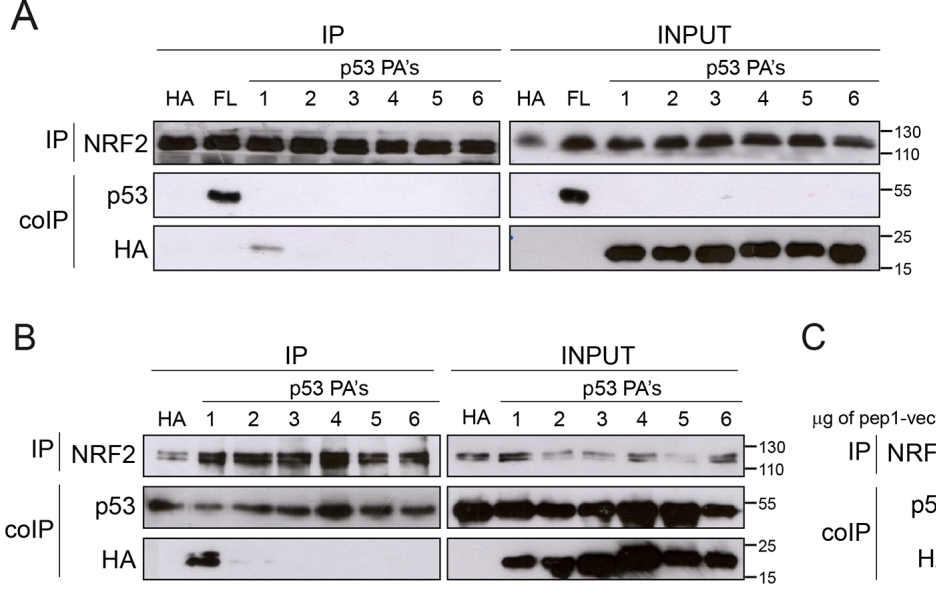

C
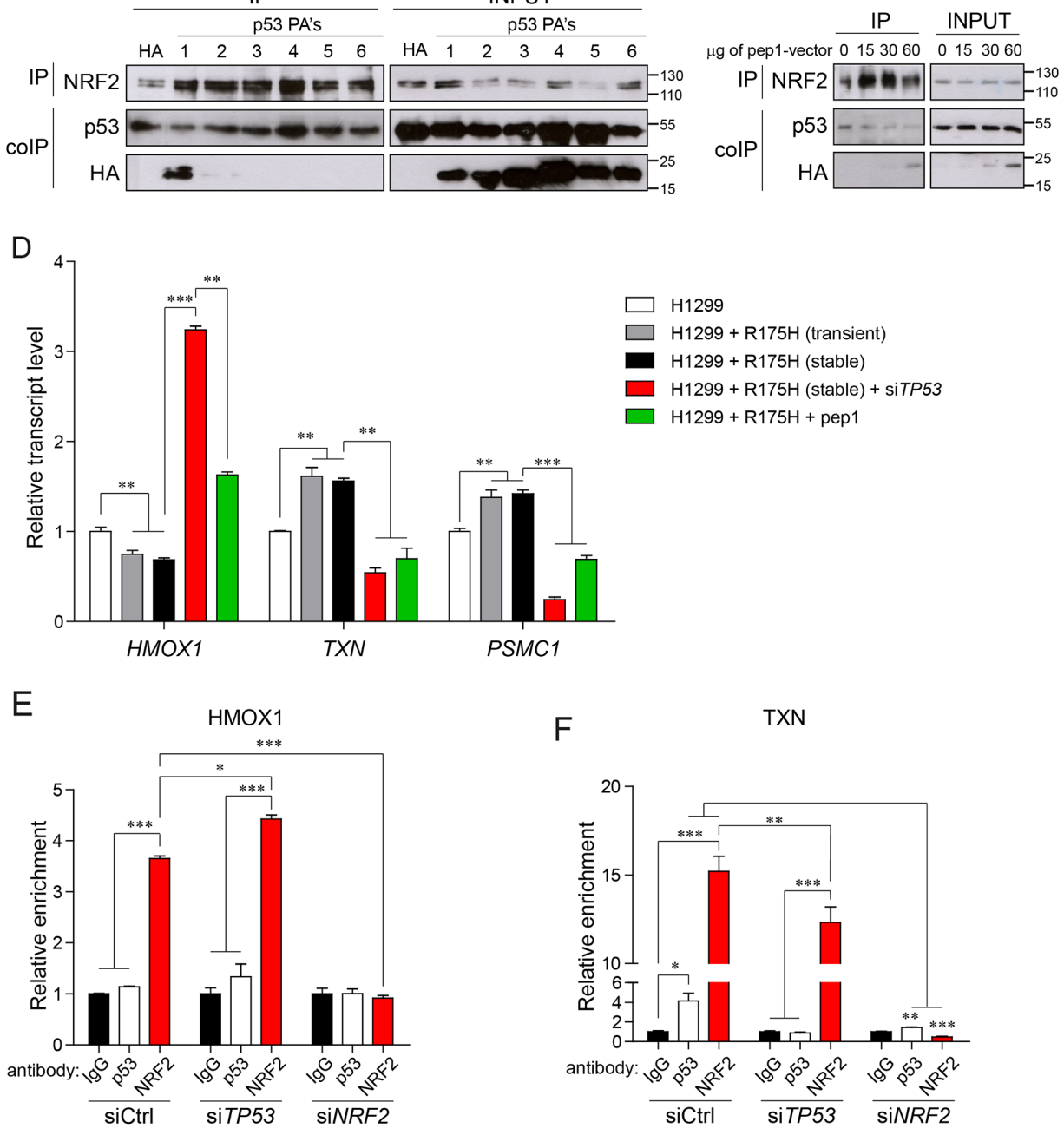

$\mathrm{F}$

TXN

Figure 2: Mutant p53-NRF2 interaction is crucial for regulating NRF2 targets. (A) Western blot analysis of coimmunoprecipitation (coIP) of NRF2 with p53R175H and with p53 peptide aptamers (p53 PA's) in lysates from H1299 cells upon transient transfection with empty- (HA), p53R175H- (FL) or p53 PA vectors. NRF2-antibody immunoprecipitated proteins (IP) and input cell lysates (INPUT) were analyzed by western blot with the indicated antibodies; size markers are indicated. (B) Western blot analysis of the interaction of NRF2 with mutant p53 and p53 PA's in co-IP assay upon overexpression of empty- (HA) or TNV p53 PA's vectors in H1299 cells stably overexpressing p53R175H. Upon IP with the anti-NRF2 antibody, immunoprecipitated proteins (IP) and input cell lysates (INPUT) were analyzed by western blot with the indicated antibodies; size markers are indicated. (C) Western blot analysis of the interaction of NRF2 with mutant p53 in co-IP assay upon overexpression of empty- (0) or increasing amounts of pep1-encoding vector $(15 \mu \mathrm{g}, 30 \mu \mathrm{g}, 60 \mu \mathrm{g})$ into H1299 cells stably overexpressing p53R175H. Upon IP with anti-NRF2 antibody, immunoprecipitated proteins (IP) and input cell lysates (INPUT) were analyzed by western blot with the indicated antibodies; size markers are indicated. (D) Expression of selected NRF2 targets in $\mathrm{H} 1299$ cells transfected with empty- or p53 R175H vector (R175H) alone or in combination with mutant p53 silencing (siTP53) or with pep1 overexpression. Expression levels are given relative to $A C T B$. (E,F) Chromatin immunoprecipitation (ChIP) of NRF2-binding regions from HMOX1 (E) and TXN (F) transcription regulatory sequences using anti-p53 or anti-NRF2 antibodies upon siRNA-mediated silencing of mutant TP53, NRF2 or control siRNA (siCtrl). ChIP enrichment in anti-p53 (DO-1) and anti-NRF2 antibody IP is compared to the control IgG antibody IP. Data shown in D-F are the means \pm s.d. of $n=3$ independent experiments, ANOVA test with Bonferroni correction: ${ }^{*} p<0.05,{ }^{* *} p<0.01,{ }^{* * *} p<0.001$. 
MB-231 ${ }^{\text {+shp53/+HA R280K) }}$ we observed a rescue of TXN gene expression and of the corresponding thioredoxin (Trx) protein level, coupled with the transcriptional repression of $H M O X 1$

(Figure 1E and Supplementary Figure 2E). Heme oxygenase
1 (HO-1) protein levels were undetectable by western blot analysis in unstressed conditions (data not shown).

We next evaluated whether the effect of mutant p53 on NRF2 targets involved a modulation of NRF2 protein
A

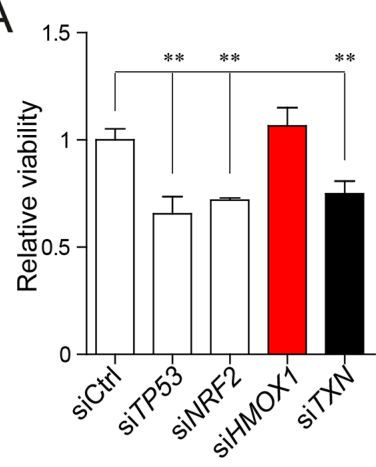

C

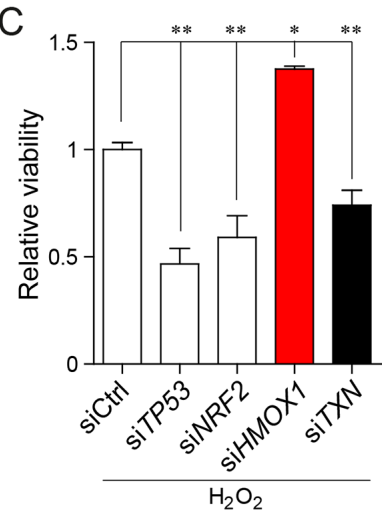

E

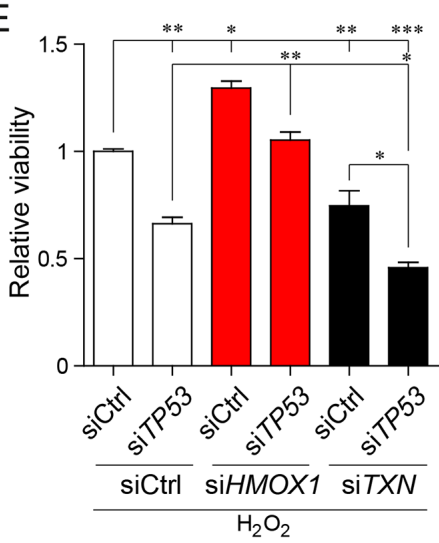

B

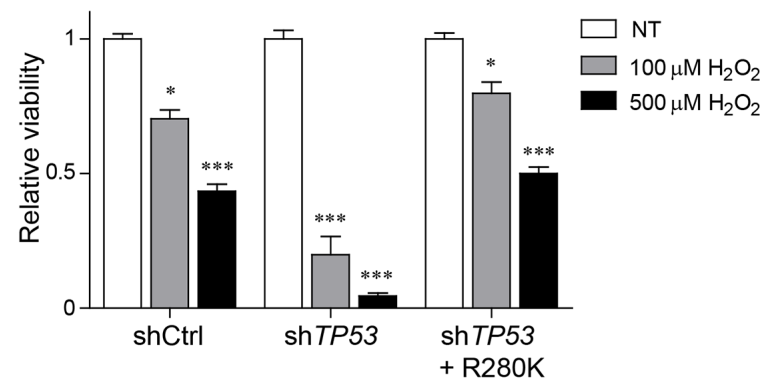

D

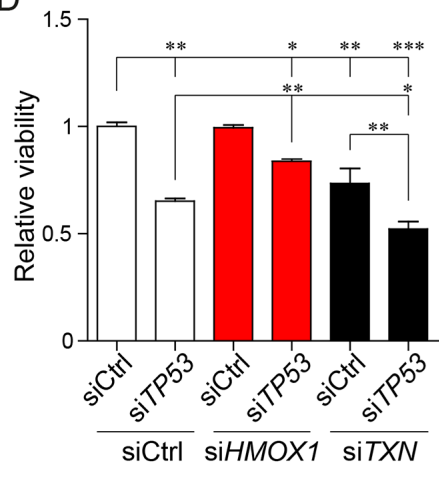

$\mathrm{F}$

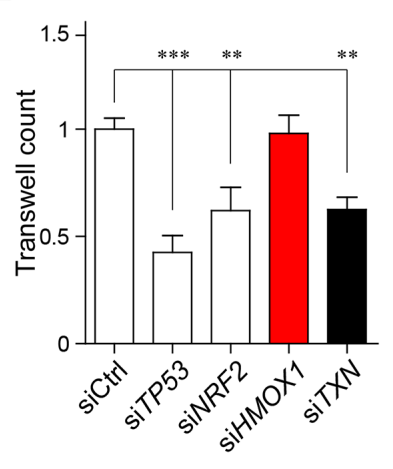

G

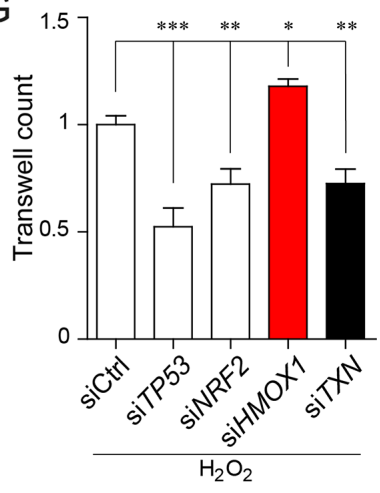

Figure 3: Cancer cell viability and migration under oxidative stress rely on the mutant p53-depedent differential regulation of NRF2 targets. (A) Viability measurement of MDA-MB-231 cells upon TP53, NRF2, TXN, HMOX1 or control silencing. (B) Viability measurement of MDA-MB-231 cells stably silenced for control (shCtrl), TP53 (shTP53), or TP53 together with stable mutant p53 R280K overexpression (shTP53 + R280K) in unstressed (NT) or under oxidative stress conditions $\left(100 \mu \mathrm{M}\right.$ or $500 \mu \mathrm{M} \mathrm{H}_{2} \mathrm{O}_{2}, 48$ hours treatment). (C) Viability measurement of MDA-MB-231 cells upon TP53, NRF2, TXN, HMOX1 or control silencing under low oxidative stress conditions induced by overnight treatment with $100 \mathrm{\mu M} \mathrm{H}_{2} \mathrm{O}_{2}$. (D) Viability measurement of MDA-MB-231 cells upon co-silencing of p53 and NRF2 downstream targets (HMOX1 or TXN). (E) Viability measurement of MDA-MB-231 cells after co-silencing of p53 and NRF2 downstream targets ( $H M O X 1$ or TXN) under low oxidative stress conditions induced by overnight treatment with $100 \mu \mathrm{M} \mathrm{H}_{2} \mathrm{O}_{2}$. (F) Transwell migration assays of MDA-MB-231 cells upon TP53, NRF2, TXN, HMOX1 or control silencing. (G) Transwell migration assays of MDA-MB-231 cells upon TP53, NRF2, TXN, HMOX1 or control silencing under low oxidative stress conditions induced by overnight treatment with $100 \mu \mathrm{M} \mathrm{H}_{2} \mathrm{O}_{2}$. Data shown in A-G are the means \pm s.d. of $\mathrm{n}=3$ independent experiments, ANOVA test with Bonferroni correction: ${ }^{*} p<0.05,{ }^{* *} p<0.01,{ }^{* * *} p<0.001$. 
levels. We performed both ectopic expression of two TP53 mutants in MCF10A and silencing of mutant TP53 in different cell lines (MDA-MB-231, MDA-MB-468, BT549 and SUM149) and analyzed NRF2 levels. As shown in Supplementary Figure 3A-3C modulation of mutant $\mathrm{p} 53$ did not have a strong impact on NRF2 protein levels. Taken together these results indicate that mutant p53 exerts both positive and negative control over NRF2 transcriptional activity without altering the NRF2 protein levels.

\section{Mutant p53-NRF2 interaction is crucial for regulating NRF2 targets in mutant p53 bearing cancer cells}

We have previously shown that mutant p53, via its DNA-binding domain, interacts with NRF2 and cooperatively both proteins activate proteasome subunit genes' transcription [14]. We have also hypothesized that the interaction between mutant p53 and NRF2 is crucial for the transcriptional regulation of proteasome subunit genes and possibly, of other NRF2 targets but we did not characterize in detail the region of p53 involved in NRF2 binding. To this aim we used here a previously described protein scaffold system to expose peptide aptamers in cells for protein interaction studies [25]. Six peptides of the length of 30 amino acids containing sequences corresponding to the human p53 DNA-binding domain (DBD) were expressed inside the scaffold protein fused with HA tag cloned within an eukaryotic expression vector [25] (Supplementary Figure 3D). The p53-null H1299 cancer cells were transfected with plasmids expressing the full-length mutant p53 R175H or the six peptides spanning the DBD of mutant p53 and cell lysates were subjected to immunoprecipitation of endogenous NRF2. As shown in Figure 2A among the six peptides only peptide1 (pep1) corresponding to aa 98-128 of the mutant p53 DBD was co-immunoprecipitated with NRF2. Moreover, in H1299 cells stably overexpressing full-length mutant p53, ectopic expression of the plasmid vector carrying pep1 was able to compete with mutant p53 full-length protein for binding to endogenous NRF2, as shown by co-immunoprecipitation assays with the anti-NRF2 antibody (Figure 2B). This effect increased when increasing amount of the pep1 encoding vector was used (Figure 2C).

We next verified whether this peptide was able to interfere with the mutant p53-dependent regulation of NRF2 transcriptional targets. As shown before [14], introduction of mutant $\mathrm{p} 53$ variant $\mathrm{R} 175 \mathrm{H}$ in the $\mathrm{p} 53$-null background of H1299 cells caused the up-regulation of proteasome subunit genes (PSMA2 and PSMC1) known targets of NRF2, and this effect was strongly counteracted by overexpressing pep1 (Supplementary Figure 3E).

Next, we asked if pep1 by preventing mutant p53/ NRF2 interaction could affect also other NRF2 targets differentially regulated by mutant p53. In H1299 cells both transient and stable overexpression of mutant p53 R175H enhanced TXN and PSMC1 gene transcription, while significantly repressed $H M O X 1$ expression (Figure 2D). Conversely, upon downregulation of mutant p53 levels with a specific siRNA, H1299 ${ }^{+ \text {mtp53R175H }}$ cells showed a significant up-regulation of $H M O X 1$ transcript and a down-modulation of TXN and PSMC1 gene transcription. We also observed comparable, opposite effects on $T X N$ and PSMC1 and on HMOX1 in mutant TP53-silenced

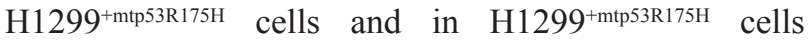
overexpressing pep1 (Figure 2D).

These results indicate that aa 98-128 of p53 are involved in the interaction of mutant p53 with NRF2 and that expression of a peptide corresponding to that sequence is able to dissociate the complex between the two proteins with a clear impact on the transcriptional regulation of NRF2 targets by mutant p53.

\section{Mutant p53 presence on ARE elements in regulatory regions of NRF2 targets is required for activation of their transcription}

To dissect the mechanism by which the concerted action of mutant p53 and NRF2 can either enhance or repress transcription, chromatin immunoprecipitation (ChIP) experiments were performed in MDA-MB-231 cells using NRF2 or p53 antibodies and the regulatory regions of both activated and repressed NRF2 target genes were analyzed.

We found out that in MDA-MB-231 cells NRF2 binds the regulatory elements of its targets even without externally applied oxidative stress (Figure 2E, 2F and Supplementary Figure 3F, 3G).

In these conditions mutant p53 is co-recruited on TXN and TXNRD1 gene promoters together with NRF2 (Figure 2F and Supplementary Figure 3G). Silencing of mutant TP53 decreased NRF2 recruitment to these regions, while silencing of $N R F 2$ completely abolished mutant p53 binding indicating that mutant p53 requires NRF2 for binding ARE sequences on activated gene promoters, an effect that we have previously shown also for proteasome subunit genes [14]. On the other hand we did not find mutant p53 binding to the promoter of ABCC3, nor to an ARE-containing distant enhancer (EN2) of HMOX1, which is a canonical regulatory element bound and activated by NRF2 [26] (Supplementary Figure $3 \mathrm{~F}$ and Figure 2E). Silencing of mutant TP53 increased the efficiency of NRF2 binding to the HMOX1 enhancer (Figure 2E).

In normal cells under unstressed conditions NRF2 resides mainly within the cytoplasm, while in cancer cells, the intracellular chronic oxidative stress causes the accumulation of a fraction of NRF2 in the nucleus in the absence of external stress stimuli $[14,27]$. Interestingly, we observed that overexpression of two different GOF 
mutant p53 variants in H1299 induced an increase in nuclear NRF2 (Supplementary Figure 4A, 4B) which was comparable to that observed upon oxidative stress induction (Supplementary Figures 2A and 4C). Moreover, when we silenced mutant TP53 expression in MDA-
MB-231 or in MCF10A overexpressing mutant p53 $\mathrm{R} 175 \mathrm{H}$, we observed that the majority of NRF2 was localized in the cytoplasm (Supplementary Figure 4D, 4E).

These results suggest that mutant p53 increases NRF2 localization to the nucleus of cancer cells where

A
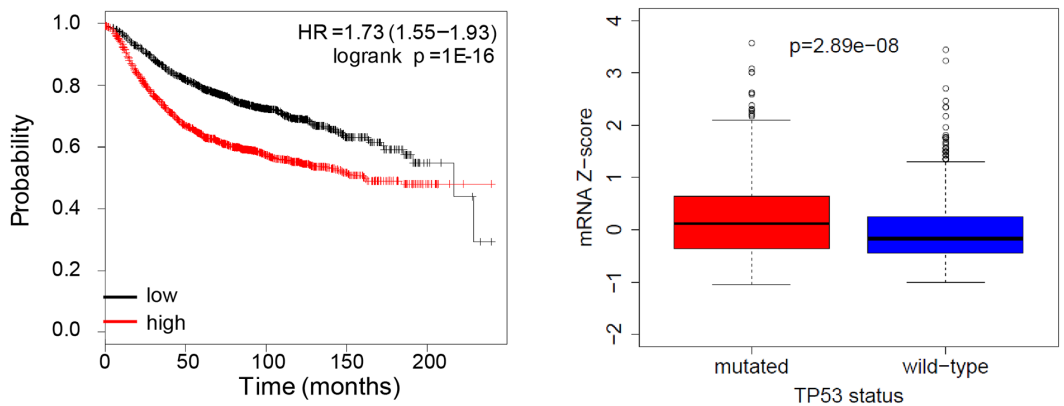

\begin{tabular}{|c|c|}
\hline TXN & Thioredoxin \\
\hline TXNRD1 & Thioredoxin Reductase 1 \\
\hline PSMC1 & Proteasome 26S Subunit, ATPase, 1 \\
\hline GCLM & Glutamate-Cysteine Ligase, Modifier Subunit \\
\hline
\end{tabular}

B
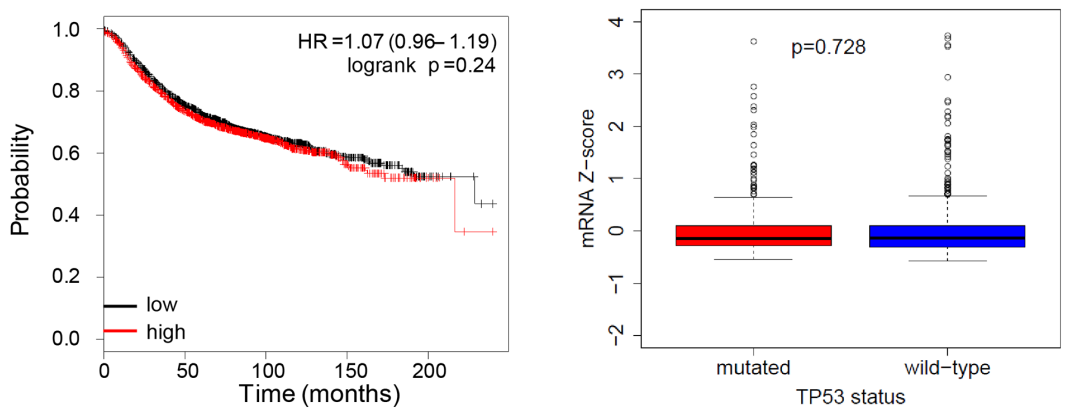

\begin{tabular}{|c|c|}
\hline HMOX1 & Heme Oxygenase 1 \\
\hline SLC7A11 & $\begin{array}{c}\text { x-CT/ sodium-independent glutamate } \\
\text { transporter }\end{array}$ \\
\hline ABCC3 & $\begin{array}{c}\text { ATP-Binding Cassette, Sub-Family C } \\
\text { (CFTR/MRP), Member 3 }\end{array}$ \\
\hline
\end{tabular}

Figure 4: NRF2 transcriptional program activated by mutant p53 is associated with poor overall prognosis and with the mutant status of $\mathbf{p 5 3}$ in breast cancer patients. (A) (upper panels) Left, association of the mutant p53 activated signature with a survival of breast cancer patients. The red curve ("high") represents the survival of patients with high expression of mutant p53 activated signature, black curve ("low") - low expression of mutant p53 activated signature. HR - hazard ratio; log-rank P - log-rank test p-value for the curves comparison. Right, association of the mutant/wt TP53 status and expression of NRF2 targets activated by mutant p53 listed in the table (TXN, TXNRD1, GCLM, PSMC1). Box plot: diff - difference in mean gene expression in mutant vs. wt p53 status samples; p-value is derived from Mann-Whitney $U$ test. Centre represents the median, box extremes indicate the first and third quartiles, and whiskers extend to the extreme values included in the interval calculated as $\pm 1.58 \mathrm{IQR} / \mathrm{sqrt}(\mathrm{n})$, where the IQR (interquartile range) is calculated as the third quartile minus the first values included in the interval calculated as $\pm 1.58 \mathrm{IQR} / \mathrm{sqrt}(\mathrm{n})$, where the IQR (interquartile range) is calculated as the third quartile minus the first quartile. (lower panel) List of genes included in the signature. (B) (upper panels) Left, association of the mutant p53 repressed signature with survival of breast cancer patients. The red curve ("high") represents the survival of patients with high expression of mutant p53 repressed signature, black curve ("low") - low expression of mutant p53 repressed signature. HR - hazard ratio; log-rank P - log-rank test p-value for the curves comparison. Right, association of the mutant/wt TP53 status and expression of NRF2 targets repressed by mutant p53 (HMOX1, $x$-CT, $A B C C 3$ ). Box plots: as in (A), diff - difference in mean gene expression in mutant vs wt p53 status samples; p-value is derived from Mann-Whitney $U$ test). (lower panel) List of genes included in the signature. 
it redirects NRF2 to ARE elements of specific genes, activating their transcription (TXN, TXNRD1), and conversely it sequesters NRF2 from other targets (HMOX1, ABCC3) leading to their downregulation.

\section{Cancer cell survival and migration under oxidative stress relies on the mutant p53- depedent differential regulation of NRF 2 targets}

$\mathrm{H}_{2} \mathrm{O}_{2}$ is a widely used inductor of oxidative stress that activates NRF2-dependent response mechanism [28$30]$ and mimics the characteristic chronic oxidative stress environment of tumor cells [31-33]. As reported by others, via $\mathrm{H}_{2} \mathrm{O}_{2}$ production, oxidative stress modulates tumor growth and spread [31,34] and sub-cytotoxic levels of $\mathrm{H}_{2} \mathrm{O}_{2}$ in tumors differentially modulate the behavior of normal and neoplastic cells [35]. In order to address the impact of the NRF2 targets activated or repressed by mutant $\mathrm{p} 53$ on mutant p53-dependent cancer cells phenotype, we performed viability experiments in cancer cells either exposed or not to exogenous oxidative stress by $\mathrm{H}_{2} \mathrm{O}_{2}$ (Figure 3A-3E and Supplementary Figure 4F).

In normal conditions, in the absence of $\mathrm{H}_{2} \mathrm{O}_{2}$, silencing of either mutant TP53 or NRF2 significantly decreased MDA-MB-231 cell viability. Similar effects were observed upon silencing of $T X N$ gene, an NRF2 target induced by mutant p53 (Figure 3A). In contrast, silencing of $H M O X 1$, an NRF2 target repressed by mutant $\mathrm{p} 53$, had no effect on the viability of MDAMB-231 cells (Figure 3A). Treatment of MDA-MB-231 breast cancer cells with $100 \mu \mathrm{M} \mathrm{H}_{2} \mathrm{O}_{2}$ (low oxidative stress) induced a $30 \%$ decrease of cell viability, while upon $500 \mu \mathrm{M}$ treatment (high oxidative stress) cell viability was reduced by $70 \%$ (Supplementary Figure $4 \mathrm{~F}$ ). As expected both low and high oxidative stress activated NRF2 and its targets, albeit to a different extent (Supplementary Figure 2A, 2B). Silencing of mutant TP53 further sensitized cells to low and high oxidative stress, but overexpression of mutant p53 in MDA-MB-231 cells, silenced for the endogenous mutant TP53 variant R280K, rescued cell survival conferring a cytoprotective effect to cancer cells (Figure 3B). In low oxidative stress conditions, silencing of $T X N$ expression further reduced cell viability, while silencing of $H M O X 1$ had a pro-survival effect (Figure 3C). Moreover, we observed that combining HMOXI and mutant TP53 silencing counteracted the impact of the sole mutant p53 silencing on cell viability in both normal and induced oxidative stress conditions, while silencing of both mutant TP53 and TXN further decreased the cell viability (Figure 3D, 3E). Under the high oxidative stress (treatment with $500 \mu \mathrm{M}$ $\mathrm{H}_{2} \mathrm{O}_{2}$ ), cancer cell viability was reduced by $90 \%$ upon silencing of either HMOXI or TXN (Supplementary Figure 4G, 4H), indicating that both antioxidant defense mechanisms have to be intact for cancer cell survival in high oxidative stress conditions.

We next wanted to evaluate the impact of $T X N$ and HMOX1 silencing also on the migration capabilities of MDA-MB-231 in both unstressed and oxidative stress conditions. As shown in Figure 3F, 3G silencing of $H M O X 1$ resulted in increased migration of MDA-MB-231 cells under low oxidative stress. In contrast, silencing of $T X N$ resulted in a drop of the migration rate both upon exposure to low oxidative stress and under normal conditions.

Altogether these results suggest that in the low oxidative stress conditions, cancer cell survival and migration depends on selective induction of a specific oxidative stress response, namely the thioredoxin system, while keeping at low levels other antioxidant systems, such as the heme oxygenase 1 system. Our data also indicate the mutant p53/NRF2 axis as a key player in finetuning of this response.

\section{Expression of NRF2 transcriptional targets activated by mutant p53 is associated with poor prognosis and with the mutant status of p53 in breast cancer patients}

Our data indicates a dual role of mutant p53 in regulating NRF2 transcriptional targets in vitro. To understand the relevance of this mechanism in vivo, we investigated the association of the expression levels of NRF2 targets that we found differentially regulated by mutant $\mathrm{p} 53$ in vitro with the mutant $\mathrm{p} 53$ status in a cohort of breast cancer patients (Figure 4). Expression of genes upregulated by mutant p53 (signature 1, Figure $4 \mathrm{~A})$ associated with the mutant status of p53 in breast cancer patients according to the TCGA dataset. Moreover, high expression of these genes showed association with poor prognosis in breast cancer (Figure 4A), in contrast with the expression of genes downregulated by mutant p53 (signature 2, Figure 4B). Moreover, expression of signature 2 or of $N R F 2$ did not correlate with the mutant status of p53 in the studied cohort (Figure 4B and Supplementary Figure 5A).

\section{Concomitant treatment with Auranofin and APR-246 selectively kills cancer cells bearing mutant p53}

Having demonstrated the relevance of NRF2 modulation by mutant $\mathrm{p} 53$ on the viability and migration of cancer cells, we next asked if inhibiting the mutant p53/NRF2 axis could have a synergistic killing effect on cancer cells bearing TP53 GOF mutations. In particular, we sought whether inhibiting mutant p53 could impair the growth of mutant $\mathrm{p} 53$ bearing cancer cells with perturbed NRF2 activity. In order to address this question, we investigated whether silencing of NRF2 expression would 
specifically sensitize mutant p53 bearing cells to treatment with APR-246, a drug that binds and converts mutant p53 into a wild type-like, active protein [36]. Indeed, in MDAMB-231 and MCF10A ${ }^{+\mathrm{R} 280 \mathrm{~K}}$ cells silenced for $N R F 2$, treatment with APR-246 significantly reduced viability, while wt p53 bearing cells (MCF10A or MCF7) silenced for $N R F 2$, were not affected by APR-246 (Supplementary Figure $5 \mathrm{~B})$. These results indicate that targeting of mutant p53 with APR-246 synergizes with depleting its partner protein NRF2.

We have demonstrated here that the thioredoxin system is a downstream target and effector of the mutant
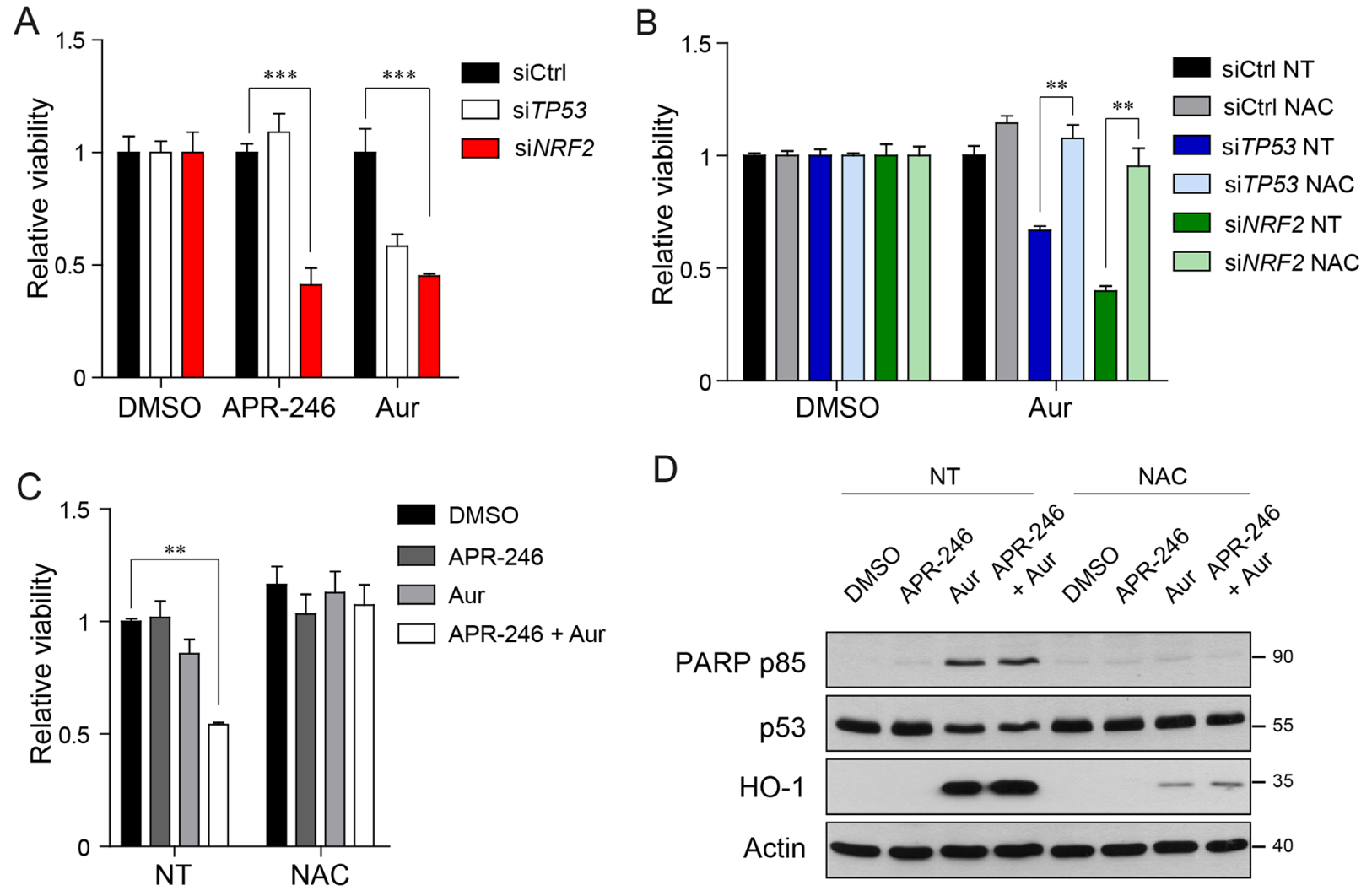

D
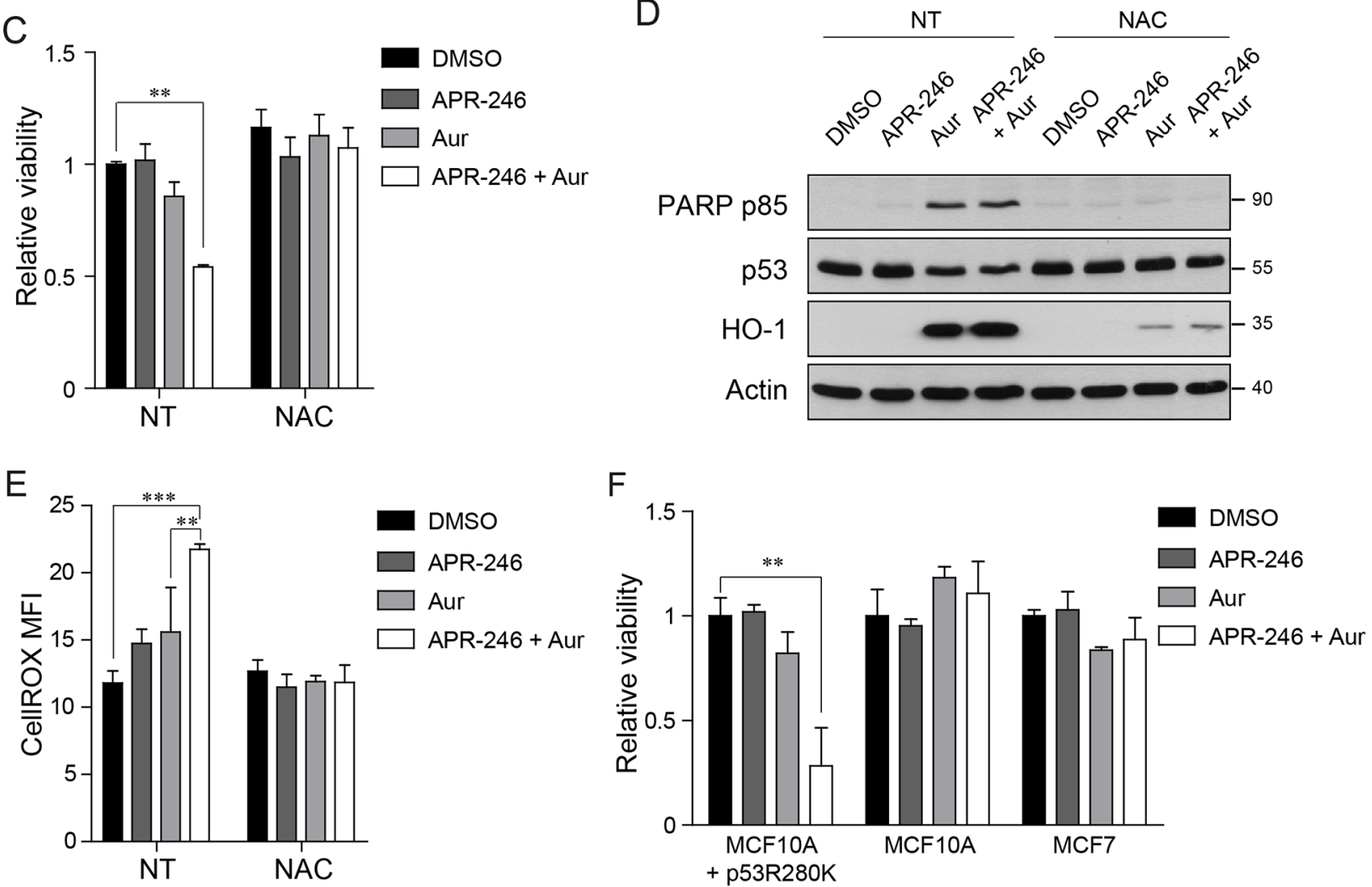

Figure 5: Concomitant treatment of Auranofin and APR-246 selectively kills cancer cells bearing mutant p53. (A) Viability measurements of MDA-MB-231 cells upon TP53, NRF2 or control silencing and 24 hours treatment with APR-246 (25 $\mu$ M), Auranofin $(2 \mu \mathrm{M})$ or DMSO. (B) Viability measurements of MDA-MB-231 cells upon TP53, NRF2 or control silencing and 24 hours treatment with the indicated compounds (NAC $5 \mathrm{mM}$, Auranofin $2 \mu \mathrm{M}$, DMSO). (C) Viability measurements of MDA-MB-231 cells upon 24 hours treatment with upon 24 hours treatment with the indicated compounds (APR-246 $25 \mu \mathrm{M}$, Auranofin $2 \mu \mathrm{M}$, NAC 5mM, DMSO). (D) Western blot analysis of the apoptosis marker PARP p85 in cell lysates of MDA-MB-231 cells treated as in (C). Representative of 2 biological replicates is shown. Actin levels are reported as loading control; size markers are indicated. (E) CellROX mean fluorescence intensity (MFI) of MDA-MB-231 cells treated as in (C). (F) Viability measurements of MCF10A cells overexpressing p53R280K (MCF10A + p53R280K), MCF10A cells, and MCF7 cells respectively. Data shown in A-C, E, F are the means \pm s.d. of $n=3$ independent experiments, ANOVA test with Bonferroni correction: ${ }^{*} \mathrm{p}<0.05,{ }^{* *} \mathrm{p}<0.01,{ }^{* * *} \mathrm{p}<0.001$. 
p53/NRF2 axis (Figures 2D, 2F, 3 and Supplementary Figure $3 \mathrm{G})$. This prompted us to test the efficacy of a combined inhibition of mutant p53 and of the TXN/TXNRD1 system in killing cancer cells expressing mutant p53. Of note, a specific inhibitor of thioredoxin reductase, Auranofin, has been already approved for clinical use as an antirheumatic agent [37] and clinical trials are currently evaluating its effects on various cancer types (https://clinicaltrials.gov/ct2/).

We treated MDA-MB-231 cells silenced for mutant $T P 53, N R F 2$ or control siRNA with $2 \mu \mathrm{M}$ Auranofin. Upon treatment, cells showed a significant viability decrease in mutant TP53 and in NRF2 silencing conditions (Figure 5A). In mutant TP53 and in NRF2 silenced cells the viability decrease caused by Auranofin was rescued by adding $\mathrm{N}$-acetylcysteine (NAC), a compound which restores the antioxidant potential of cells [9] (Figure 5B), indicating that the viability decrease is caused by defective ROS neutralization. This result suggested that, in cancer cells silenced for mutant TP53 or NRF2, Auranofin causes the viability decrease by inducing high levels of intracellular ROS the cells can not cope with, due to impairment of the mechanism activating the required antioxidant systems.

Hence, we next investigated if combining inhibition of mutant p53 by APR-246 and inhibition of the thioredoxin system by Auranofin could cause a specific lethality of mutant p53 bearing cancer cells. As shown in Figure 5C the co-treatment led to a significant downregulation of MDA-MB-231 cell viability and enhanced apoptosis, as indicated by the accumulation of PARP p85 fragment (Figure 5D). In these conditions we also observed increased protein levels of HO-1 and a decrease in Trx protein levels (Figure 5C and Supplementary Figure 5C). We next assessed the production of ROS in response to the drug treatment by CellROX FACS analysis. The combination treatment with Auranofin and APR-246 induced significantly higher accumulation of ROS with respect to control cells and to cells treated with either APR-246 or Auranofin (Figure 5E), further indicating that the increased production of ROS levels beyond a manageable threshold could be the reason why combining treatments produces synergistic effects in killing cancer cells bearing mutant p53. Accordingly, we observed that the viability decrease and the apoptosis induction caused by the combination treatment were rescued by NAC addition (Figure 5C-5E).

A synergistic effect of the Auranofin/APR-246 treatment was observed also in MCF $10 \mathrm{~A}^{+\mathrm{mtp} 53 \mathrm{R} 280 \mathrm{~K}}$, while cells bearing wtp53, like MCF10A or MCF7, were not significantly affected by the drug combination in the investigated concentrations (Figure 5F).

\section{DISCUSSION}

In normal cells, the transcription factor NRF2 is a key regulator of antioxidant pathways acting as a defense mechanism against oxidative stress. However, NRF2 activity was shown to be essential also for the survival of cancer cells by protecting them from the oxidative environment that characterizes tumors [1]. Indeed, NRF2 has been shown to be activated by oncogenic signaling, resulting in enhanced cytoprotection of cancer cells [5].

We demonstrate here that missense mutant p53 is a key interactor of NRF2 and a modulator of its transcriptional program, through which it selectively promotes a specific pro-survival oxidative stress response in cancer cells.

While NRF2-regulated transcripts, including diverse components of the oxidative stress response, are all activated upon introduction of activated Ras and Myc into breast epithelial cells, mutant p53 leads to upregulation of thioredoxin $(T X N)$ and proteasome (PSM) systems, but to repression of heme oxygenase 1 gene (HMOXI) among other NRF2 targets. The difference with other oncoproteins known to activate NRF2 is likely due to the fact that while Ras or Myc family proteins primarily activate NRF2 transcription directly $[4,5]$, mutant p53 modulates its activity via protein interaction $[14,38]$ and this binding is required for regulating activation and repression of specific NRF2 targets by mutant p53. We mapped the region of p53 involved in the binding to NRF2 into the initial region of the p53's DNA-binding domain (98-128aa). Of note, this region, which has been shown to be structurally affected in multiple mutant p53 variants, is bound by APR-246 [39], a drug inhibiting mutant $\mathrm{p} 53$ 's gain-of-function and reactivating p53 wildtype conformation and properties [36]. The localization of the mutant p53's region interacting with NRF2 in this domain could explain the observed binding of NRF2 to several missense p53 mutant variants and its disruption by APR-246 [14].

Our results indicate that mutant p53 binding to NRF2 leads to an increased nuclear localization of NRF2 on ARE-containing regulatory sequences, leading to specific effects on NRF2 targets' transcription, resulting in the transcriptional activation of genes such as TXN and the proteasome encoding genes, and in the repression of others such as $H M O X 1$ and $A B C C 3$ (Figure 6). In addition, our experiments suggest that NRF2 targets can be divided in two categories. The first category consists of NRF2 inducible genes whose expression is low in the absence of oxidative stress $(A B C C 3$ and $H M O X 1$; Supplementary Figures 2D and 5C). The other group consists of basally active NRF2 targets whose expression is already high in the same conditions (TXN and TXNRD1; Supplementary Figures 2D and 5C). Consistently, our ChIP results indicate that the binding of NRF2 to the regulatory elements of its basal targets is much higher than the binding measured for inducible targets. Our results indicate that mutant p53 might selectively contribute to repress the inducible NRF2 targets and cooperate to activate the basal ones. 
The biological effect of the mutant p53/NRF2 interplay is an increased survival of cancer cells under oxidative stress. The presence of increased ROS levels is a known feature of tumor microenvironment $[40,41]$ and induction of the thioredoxin/thioredoxin reductase (TXN/TXNRD1) system is known to be beneficial for the survival of cancer cells $[9,42]$. Indeed $T X N$ is a critical NRF2 target and belongs to the NRF2 target signature activated by mutant p53, whose increased expression is associated with poor prognosis in breast cancer. Accordingly, high expression of $T X N$ and $T X N R D 1$ has been previously associated to high grade breast cancers [43]. Consistently, we show here that silencing of $T X N$ strongly decreases the survival and migration of breast cancer cells under oxidative stress. In contrast, silencing of $H M O X 1$ has opposite effects. In agreement, several studies suggest that, while having cytoprotective functions in untransformed cells, $H M O X 1$ plays a cytotoxic role in cancer cells $[44,45]$.

Overall our results shed new light onto the complex role of antioxidant systems in cancer initiation and progression. Increased production of ROS is essential to enable and sustain a highly metastatic phenotype [46]. However by preventing an excess of damage due to ROS accumulation, antioxidant systems such as thioredoxin or glutathione are also required for cancer initiation, and inhibition of these ROS scavenging mechanisms, combined with pro-oxidizing agents, seems to be effective in the treatment of chemoresistant tumors $[9,40$, 41, 47, 48].

On the basis of our observations, we tested a combinations of drugs aimed at blocking the biological effects exerted by the mutant p53-NRF2 axis in cancer cells. Our results indicate that breast cancer cells expressing mutant p53 can be efficiently eliminated by combining the two drugs APR-246 and Auranofin. The first one is a covalent inhibitor of mutant p53 that was also described to affect the cellular redox status by targeting selenoprotein thioredoxin reductase 1 [49], while Auranofin is a known inhibitor of the thioredoxin system [50]. Recently, multiple reports have indicated that targeting the thioredoxin system with various drugs could be an efficient strategy for killing chemoresistant cancer cells [9, 37, 50-52]. Indeed, Auranofin and APR-246 in combination turned out to synergistically affect cancer cell survival by blocking mutant p53-depentend antioxidant systems both directly and indirectly. Interestingly, in a recent study mutant $\mathrm{p} 53$ was shown to mediate the repression of the NRF2 target gene SLC7A11 and a concomitant use of APR-246 with a glutathione synthesis

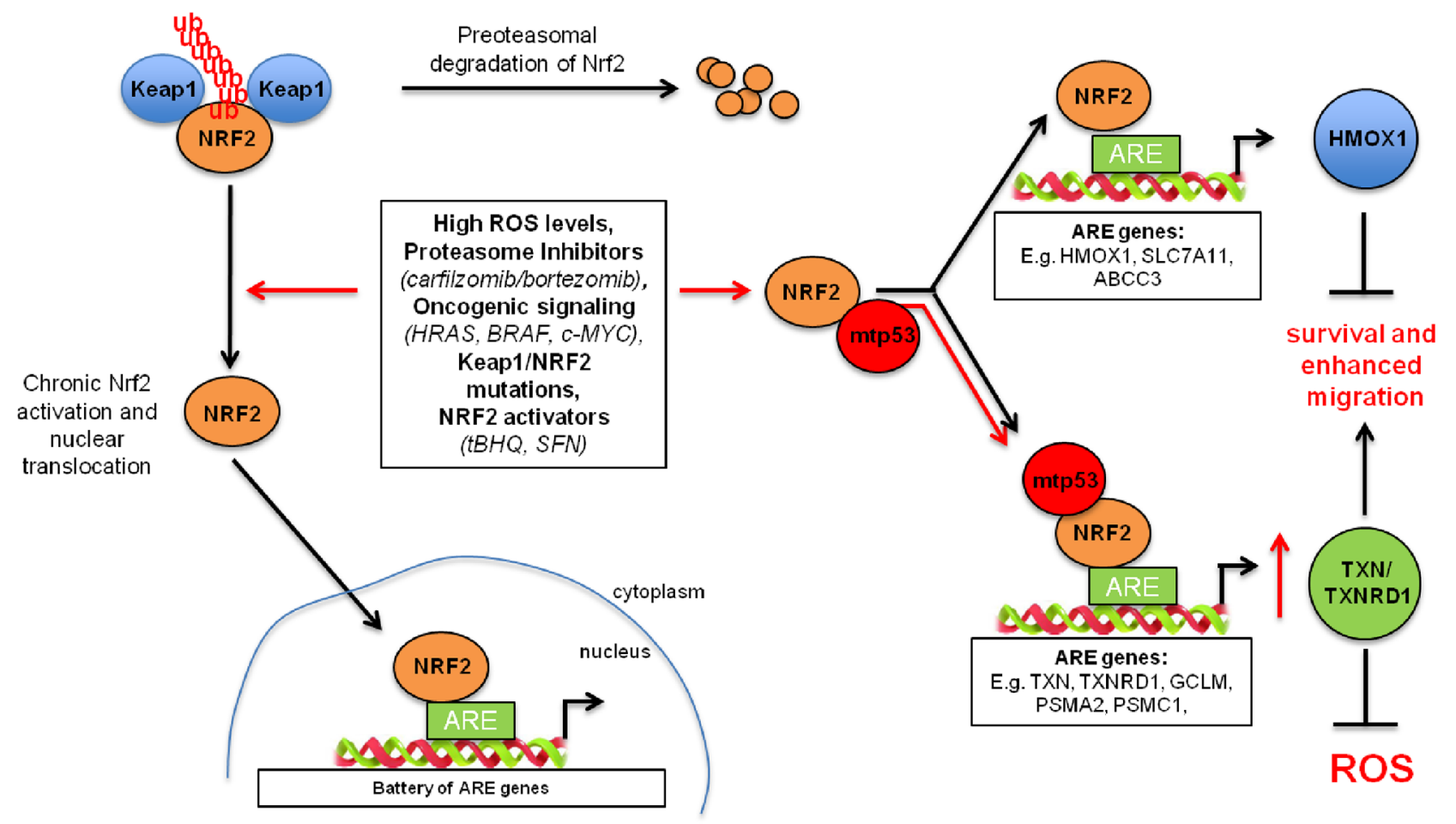

Figure 6: Model representing mutant p53-mediated tuning of the NRF2-dependent antioxidant pathway. Left, in normal conditions, NRF2 is bound by its inhibitor Keap1 and it is directed for proteasomal degradation. Upon activation (e.g. oncogenes, oxidative stress), NRF2 translocates into the nucleus where it binds to ARE (antioxidant responsive element) sequences within promoters of target genes. Right, mutant p53, when expressed, selectively activates NRF2 downstream targets, thioredoxin and proteasome systems. This effects in acquiring the resistance to microenvironmental stress. At the same time mutant p53 by increasing the presence of NRF2 on the gene promoters of TXN or TXNRD1 sequesters NRF2 from canonical NRF2 regulatory elements of other NRF2 targets (e.g. HMOX1). 
inhibitor was revealed as an approach to eliminate cancer cells with mutant p53 [38]. This result suggests that understanding of the mutant p53-depedent tuning of the NRF2 program may result in several efficient anti-cancer treatment strategies.

Our work revealed the existence of a mutant p53/ NRF2 axis that specifically exploits the thioredoxin system to sustain the survival of breast cancer cells under oxidative stress. These findings provide important advances in the understanding of NRF2 regulation in cancer and open up new therapeutic opportunities for breast cancers expressing mutant p53.

\section{MATERIALS AND METHODS}

\section{Cell lines and treatments}

All cell lines were purchased from ATCC. Human cell lines MDA-MB-231 (p53 R280K), MDAMB-468 (p53 R273H) were cultured in DMEM medium (BioWhittaker) supplemented with 10\% FCS (ECS0180L, Euroclone), and antibiotics (DE17-602E, Lonza). BT-549 (p53 R249S), H1299 (p53-null) cells were cultured in RPMI medium (BioWhittaker) supplemented with 10\% FBS and antibiotics. SUM-149 (p53 M237I) cells were cultured in DMEM:F12 Ham's medium 1:1, supplemented with 10\% FCS and antibiotics. MCF7 (p53 wt) were cultured in EMEM (BioWhittaker), supplemented with 1\% non-essential aminoacid solution (Sigma), 10\% FBS and antibiotics. MCF10A (p53 wt, shTP53 and stable mutant p53 overexpressing cell lines) cells were maintained in DMEM:F12 Ham's medium 1:1, supplemented with 5\% horse serum, insulin $(10 \mu \mathrm{g} / \mathrm{ml})$, hydrocortisone $(0.5$ $\mu \mathrm{g} / \mathrm{ml}$ ) and epidermal growth factor (EGF $20 \mathrm{ng} / \mathrm{ml}$ ), if needed - with addition of selection antibiotics.

All human cell lines were subjected to STR genotyping with PowerPlex 18D System and confirmed in their identity comparing the results to reference cell databases (DMSZ, ATCC, and JCRB databases). Mutant p53 cell lines have been confirmed to express indicated mutant TP53 variants by sequencing of the full-length p53 mRNA [14]. All the cell lines have been tested by PCR/IF for the Mycoplasma presence. No cell lines used in this study were found in the database of commonly misidentified cell lines that is maintained by ICLAC and NCBI Biosample. $\mathrm{H}_{2} \mathrm{O}_{2}$ (Sigma 216763), menadione (Sigma M5625), sodium arsenite (Sigma S7400), Auranofin (Enzo Life Sciences BML-28420100) and NAC (N-Acetyl-L-Cysteine, Sigma A7250) were resuspended and used as indicated in the respective datasheets.

\section{Plasmids}

pSR-shRNAp53 PuroR used to stably silence TP53 expression was a kind gift of R. Agami. si/shRNA resistant
N-terminally HA-tagged p53 constructs p53R280K and p53R175H were generated by first introducing 4 silent point mutations in the region targeted by p53 siRNA\#1/ shRNA by site-directed mutagenesis in pcDNA-HA-p53, subsequent introduction of missense point mutations and subcloning of sequenced p53 cds constructs to pMSCVHA BlastR retroviral vector.

\section{Transfection}

For retrovirus production (stable silencing of TP53 and ectopic overexpression of mutant p53s) low confluent HEK 293GP packaging cells were transfected with appropriate vectors by calcium phosphate precipitation. After 48-72 hours the virus-containing medium was filtered and added to target cells (MDA-MB-231, MCF10A or H1299). Cells were selected with puromycin $(0.5 \mu \mathrm{g} / \mathrm{ml})$ and/or blasticidin $(2 \mu \mathrm{g} / \mathrm{ml})$.

H1299 cells were transfected using Lipofectamine 2000 reagent (Invitrogen) following the manufacturer's instructions.

For siRNA transfections, all cells lines were transfected at $40-60 \%$ confluence with 24 hours interval (to increase efficiency of silencing), with $50 \mathrm{nM}$ siRNA oligonucleotides using Lipofectamine RNAiMax (Invitrogen), following manufacturer's instructions. After 48 hours cells were processed. siRNAs coding sequence used in this work are listed in the Supplementary Table 1.

\section{Total RNA extraction and RT-qPCR analysis}

Total RNA was extracted with QIAzol (Qiagen) following manufacturer's instructions. $1 \mu \mathrm{g}$ of total RNA was reverse-transcribed with QuantiTect Reverse Transcription (Qiagen). Real-time qPCR in technical duplicates from each biological replicate was performed

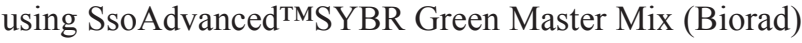
on a CFX96 Real-Time PCR System (Biorad). Expression levels are given relative to $A C T B, G A P D H$ or histone H3. The list of qPCR primers used is provided in the Supplementary Table 2. Key NRF2 downstream targets analyzed in Figure 1A were selected from available datasets. For the following experiments we narrowed down the signatures to the most strongly regulated genes by mutant p53.

\section{ChIP}

Chromatin was immunoprecipitated with p53 DO-1 (Santa Cruz) or NRF2 antibody (Abcam), as previously described [14]. As negative controls IgGs purified from rabbit or mouse serum were used. Coimmunoprecipitated DNA was analyzed by real-time PCR on a CFX96 Real-Time PCR System (Biorad), using SsoAdvanced ${ }^{\mathrm{TM}}$ SYBR Green Master Mix (Biorad). Promoter occupancy was calculated as percent of input 
chromatin immunoprecipitated using the $2^{-\mathrm{DCt}}$ method. Primer sequences are shown in the Supplementary Table 3.

\section{Statistics and reproducibility}

The statistical analysis of experimental results is described in the figure legends, along with number of biological replicates and plotted error types (s.d. standard deviation). Statistic tests were performed and $p$ value thresholds were obtained using GraphPad 6.0.

\section{Patient survival and mutation status association analysis}

To verify the correlation of the gene signatures and breast cancer clinical data, survival analysis was performed on a breast cancer meta-dataset composed by 3458 samples using the $\mathrm{Km}$-plotter online analysis tool [53]. In order to perform the analysis on the greatest possible number of patients, for each gene, we selected only HGU133A probe-sets. The samples were split into two groups according to median expressions of the proposed signatures. The two groups were then compared by survival analysis. The Kaplan-Maier curves of relapse free survival time (RFS), the hazard ratio with 95\% confidence intervals and log-rank test p-values were calculated. For each signature we selected the top 3 or 4 genes up-regulated or down-regulated by mutant $\mathrm{p} 53$.

Gene expression data, TP53 mutation status and clinical annotation for Breast Invasive Carcinoma, (TCGA datasets) have been obtained from Cancer Genomics Data Server using the cgdsr package for R (https://cran.rproject.org/web/packages/cgdsr/index.html). The datasets were chosen for analysis according to the wt TP53 vs mutant TP53 status availability, with TP53-null samples excluded. For each patient we defined the levels of mtp53 upregulated or mtp53 not upregulated signatures expression as the mean of the expression values of all the genes included in the signature. The genes composing each used signature are described in Figure 4A, 4B. The statistical differences between the distributions of expression values in the two molecular conditions (mutated TP53 and wt TP53) were calculated by MannWhitney $U$ test in $\mathrm{R} /$ Bioconductor environment (R Core Team, 2013).

Pearson's Chi-squared test with Yates' continuity correction has been performed to test independence between TP53 status and a signature expression. All statistical analysis has been performed using $\mathrm{R}$ statistical analysis environment.

\section{Western blot analysis}

Total cell extracts were prepared in RIPA buffer without SDS (150mM NaCl, 50mM Tris-HCl pH8, 1mM EDTA, 1\% NP-40, 0.5\% Na-deoxycholate) supplemented with $1 \mathrm{mM}$ PMSF, $5 \mathrm{mM} \mathrm{NaF}, 1 \mathrm{mM} \mathrm{Na} 3 \mathrm{VO} 4,10 \mu \mathrm{g} /$ ml CLAP protease inhibitor cocktail (Sigma). Protein concentration was determined with Bio-Rad Protein Assay Reagent (Bio-Rad). Lysates were resolved by SDS/PAGE and transferred to nitrocellulose (Millipore). Western blot analysis was performed according to standard procedures using primary antibodies listed in Supplementary Table 4. Western blots experiments were performed in at least 2 biological replicates, the representative is shown.

\section{Cell fractionation}

Cells were scraped in PBS and washed two times. The pellet obtained after the last centrifugation was resuspended in Cytoplasmic-buffer (10mM HEPES $\mathrm{pH} 7.9,1.5 \mathrm{mM} \mathrm{MgCl} 2,10 \mathrm{mM} \mathrm{KCl}, 0.5 \mathrm{mM}$ DTT, $0.1 \%$ NP-40) supplemented with inhibitors (1mM PMSF, 5mM $\mathrm{NaF}, 10 \mu \mathrm{g} / \mathrm{ml}$ CLAP, $1 \mathrm{mM} \mathrm{Na} 3 \mathrm{VO} 4)$; lysis was obtained gently pipetting a couple of times. After 3 ' in ice, lysates were centrifuged at $2500 \mathrm{~g}$ for $5^{\prime}$ at $4^{\circ} \mathrm{C}$; the supernatant was collected as the cytoplasmic fraction. The pellet was washed twice in Wash-buffer (10mM HEPES pH7.9, 1.5mM MgCl2, $10 \mathrm{mM} \mathrm{KCl,} \mathrm{0.5mM} \mathrm{DTT)} \mathrm{and} \mathrm{then} \mathrm{Nuclei}$ in the pellet were resuspended in Nuclear-buffer $(20 \mathrm{mM}$ HEPES pH7.9, 1.5mM MgCl2, 420mM NaCl, 0.2mM EGTA, 0.5mM DTT, 25\% glycerol) supplemented with inhibitors (1mM PMSF, $5 \mathrm{mM} \mathrm{NaF}, 10 \mu \mathrm{g} / \mathrm{ml} \mathrm{CLAP,} 1 \mathrm{mM}$ $\mathrm{Na} 3 \mathrm{VO} 4)$; nuclear extract was recovered by centrifugation at $15000 \mathrm{~g}$ for $15^{\prime}$ at $4^{\circ} \mathrm{C}$.

\section{Protein interaction studies}

Coimmunoprecipitation experiments with endogenous proteins were performed by lysing cells in the Co-IP buffer $(\mathrm{NaCl} 150 \mathrm{mM}$, Tris-HCl pH8 50mM, EDTA 1mM, NP40 $0.5 \%$, glycerol $10 \%$ ) with protease inhibitors. Samples were cleared by centrifugation for $30 \mathrm{~min}$ at $13000 \mathrm{~g}$ at $4^{\circ} \mathrm{C}$ and incubated overnight at $4^{\circ} \mathrm{C}$ with the specific antibody. After $1 \mathrm{~h}$ incubation with protein G-Sepharose (GE Healthcare), immunoprecipitates were washed three times in Co-IP buffer, resuspended in a sample buffer, and analyzed by western blotting. For Co-IP of endogenous p53 or NRF2, DO-1 (sc-126, Santa Cruz) and EP1808Y (ab62352, Abcam) primary antibodies were used respectively, and mouse or rabbit normal IgGs (Santa Cruz) as negative controls.

\section{Immunofluorescence}

Cells were fixed in 4\% paraformaldehyde for 20 min, washed with PBS, permeabilized with Tryton $0.1 \%$ for $5 \mathrm{~min}$ and blocked in PBS + FBS 3\% for $30 \mathrm{~min}$. Antigen recognition was done by incubating primary antibodies against $\mathrm{p} 53$ and NRF2 for $1 \mathrm{hr}$ at $37^{\circ} \mathrm{C}$, followed by incubation with AlexaFluor 568 and 488 conjugated secondary antibodies. Nuclei were counterstained with Hoechst 33342 (LifeTechnologies). Representative fluorescence images of 3 biological replicates were taken with a x 630 magnification on a Leica DM4000B 
microscope equipped with a Leica DFC420C camera and acquired with Leica Application Suite 2.5.0 R1 (Leica Microsystems).

\section{Migration assay}

Migration assay were performed by seeding cells at a density of 5,000 cells per well in 24-well PET inserts ( $8.0 \mathrm{~mm}$ pore size, Falcon). After $16 \mathrm{hr}$, cells that passed through the filter were fixed in 4\% PFA, stained with $0.5 \%$ crystal violet and counted with a $\times 20$ objective on CK30 Olympus optical microscope. Results shown are the average of 6 fields of view of 6 separate filters for each experimental condition.

\section{ROS detection}

For CellROX analysis, CellROX ${ }^{\circledR}$ Green Reagent (Thermo Fisher Scientific) was used as previously described [54]. Analyses were performed on a FACSCalibur cell sorter (Becton Dickinson) and data were analyzed with FlowJo software for Mac (FlowJo, LLC 2013-2016).

\section{Viability assay}

6- $10 \times 10^{4}$ cells were plated in 96-well plates (white, transparent bottom), after 24 hours they were treated as indicated in figures and assayed for viability using ATPlite ${ }^{\mathrm{TM}}$ OneStep reagent (Perkin Elmer), according to the manufacturer's instructions. Luminescence intensity was measured using EnSpire plate fluorometer (Perkin Elmer). 3 biological replicates were performed, for each experiments means from 3 technical replicates ( 3 wells) were used.

\section{Author contributions}

K.L. designed and performed majority of the experiments, analyzed the data, and wrote the paper. E.C. performed experiments, prepared the figures and wrote the paper. Y.C. performed the patient dataset association studies. D.W. designed, performed the ChIP experiments, supervised the project and wrote the paper. G.D.S. supervised the project, designed the experiments and wrote the paper.

\section{ACKNOWLEDGMENTS}

We thank A. Testa for reading and editing the manuscript. We acknowledge M. Fantuz and G. Pastore for technical support. We acknowledge Klas Wiman and Ulf Björklund from Aprea for sharing APR-246 compound.

\section{CONFLICTS OF INTEREST}

Authors declare no conflicts of interest.

\section{FUNDING}

Work in our lab is supported by the Italian Association for Cancer Research (AIRC) Special Program Molecular Clinical Oncology "5 per mille" (Grant n. 10016), AIRC IG (Grant n. 17659), the Cariplo Foundation (Grant n. 2014-0812), the Italian Health Ministry (RF-2011-02346976), the Italian University and Research Ministry (PRIN-2015-8KZKE3), the European Regional Development Fund Interreg Italia-Österreich (PreCanMed ITAT1009), Beneficentia-Stiftung, and Fondazione CRTrieste to G.D.S.; E.C. is supported by a Fondazione Umberto Veronesi Post-doctoral fellowship; Y.C. is supported by an AIRC/FIRC fellowship; D.W. is supported by the National Science Centre, Poland, project no 2017/25/B/NZ5/01343.

\section{REFERENCES}

1. Menegon S, Columbano A, Giordano S. The dual roles of NRF2 in cancer. Trends Mol Med. 2016; 22: 578-93.

2. Jeong Y, Hoang NT, Lovejoy A, Stehr H, Newman AM, Gentles AJ, Kong W, Truong D, Martin S, Chaudhuri A, Heiser D, Zhou L, Say C, et al. Role of KEAP1/NRF2 and TP53 mutations in lung squamous cell carcinoma development and radiation resistance. Cancer Discov. 2017; 7: 86-101.

3. Kandoth C, McLellan MD, Vandin F, Ye K, Niu B, Lu C, Xie M, Zhang Q, McMichael JF, Wyczalkowski MA, Leiserson MDM, Miller CA, Welch JS, et al. Mutational landscape and significance across 12 major cancer types. Nature. 2013; 502: 333-9.

4. Tao S, Wang S, Moghaddam SJ, Ooi A, Chapman E, Wong PK, Zhang DD. Oncogenic KRAS confers chemoresistance by upregulating NRF2. Cancer Res. 2014; 74: 7430-42.

5. DeNicola GM, Karreth FA, Humpton TJ, Gopinathan A, Wei C, Frese K, Mangal D, Yu KH, Yeo CJ, Calhoun ES, Scrimieri F, Winter JM, Hruban RH, et al. Oncogeneinduced NRF2 transcription promotes ROS detoxification and tumorigenesis. Nature. 2011; 475: 106-9.

6. Jaramillo M, Zhang D. The emerging role of the Nrf2Keap1 signaling pathway in cancer. Genes Dev. 2013; 27: 2179-91.

7. Hayes JD, Dinkova-Kostova AT. The Nrf2 regulatory network provides an interface between redox and intermediary metabolism. Trends Biochem Sci. 2014; 39: 199-218.

8. Chio IIC, Jafarnejad SM, Ponz-Sarvise M, Park Y, Rivera K, Palm W, Wilson J, Sangar V, Hao Y, Öhlund D, Wright $\mathrm{K}$, Filippini D, Lee EJ, et al. NRF2 promotes tumor maintenance by modulating mRNA translation in pancreatic cancer. Cell. 2016; 166: 963-76.

9. Harris IS, Treloar AE, Inoue S, Sasaki M, Gorrini C, Lee $\mathrm{KC}$, Yung KY, Brenner D, Knobbe-Thomsen CB, Cox MA, Elia A, Berger T, Cescon DW, et al. Glutathione and 
thioredoxin antioxidant pathways synergize to drive cancer initiation and progression. Cancer Cell. 2015; 27: 211-22.

10. Walerych D, Lisek K, Del Sal G. Mutant p53: one, no one, and one hundred thousand. Front Oncol. 2015; 5: 289.

11. Rotblat B, Melino G, Knight RA. NRF2 and p53: Januses in cancer? Oncotarget. 2012; 3: 1272-83. https://doi. org/10.18632/oncotarget.754.

12. Kalo E, Kogan-Sakin I, Solomon H, Bar-Nathan E, Shay M, Shetzer Y, Dekel E, Goldfinger N, Buganim Y, Stambolsky P, Goldstein I, Madar S, Rotter V. Mutant p53R273H attenuates the expression of phase 2 detoxifying enzymes and promotes the survival of cells with high levels of reactive oxygen species. J Cell Sci. 2012; 125: 5578-86.

13. Tung M, Lin $\mathrm{P}$, Wang $\mathrm{Y}, \mathrm{He} \mathrm{T}$, Lee MC, Yeh SD, Chen $\mathrm{C}$, Lee H. Mutant p53 confers chemoresistance in non-small cell lung cancer by upregulating Nrf2. Oncotarget. 2015; 6: 41692-705.

14. Walerych D, Lisek K, Sommaggio R, Piazza S, Ciani Y, Dalla E, Rajkowska K, Gaweda-Walerych K, Ingallina E, Tonelli C, Morelli MJ, Amato A, Eterno V, et al. Proteasome machinery is instrumental in a common gain-of-function program of the p53 missense mutants in cancer. Nat Cell Biol. 2016; 18: 897-909.

15. Hirotsu Y, Katsuoka F, Funayama R, Nagashima T, Nishida Y, Nakayama K, Engel JD, Yamamoto M. Nrf2-MafG heterodimers contribute globally to antioxidant and metabolic networks. Nucleic Acids Res. 2012; 40: 10228-39.

16. DeNicola GM, Chen PH, Mullarky E, Sudderth JA, Hu Z, Wu D, Tang H, Xie Y, Asara JM, Huffman KE, Wistuba II, Minna JD, DeBerardinis RJ, et al. NRF2 regulates serine biosynthesis in non-small cell lung cancer. Nat Genet. 2015; 47: 1475-81.

17. Chorley BN, Campbell MR, Wang X, Karaca M, Sambandan D, Bangura F, Xue P, Pi J, Kleeberger SR, Bell DA. Identification of novel NRF2-regulated genes by ChiPSeq: influence on retinoid $\mathrm{X}$ receptor alpha. Nucleic Acids Res. 2012; 40: 7416-29.

18. Schultz MA, Abdel-Mageed AB, Mondal D. The nrfl and nrf2 balance in oxidative stress regulation and androgen signaling in prostate cancer cells. Cancers (Basel). 2010; 2: 1354-78.

19. Ye P, Mimura J, Okada T, Sato H, Liu T, Maruyama A, Ohyama C, Itoh K. Nrf2- and ATF4-dependent upregulation of XCT modulates the sensitivity of T24 bladder carcinoma cells to proteasome inhibition. Mol Cell Biol. 2014; 34: 3421-34.

20. Girardini JE, Napoli M, Piazza S, Rustighi A, Marotta C, Radaelli E, Capaci V, Jordan L, Quinlan P, Thompson A, Mano M, Rosato A, Crook T, et al. A Pin1/mutant p53 axis promotes aggressiveness in breast cancer. Cancer Cell. 2011; 20: 79-91.

21. Monteiro JP, Martins AF, Nunes C, Morais CM, Lúcio M, Reis S, Pinheiro TJ, Geraldes CF, Oliveira PJ, Jurado AS. A biophysical approach to menadione membrane interactions: relevance for menadione-induced mitochondria dysfunction and related deleterious/therapeutic effects. Biochim Biophys Acta. 2013; 1828: 1899-908.

22. Loor G, Kondapalli J, Schriewer JM, Chandel NS, Vanden Hoek TL, Schumacker PT. Menadione triggers cell death through ROS-dependent mechanisms involving PARP activation without requiring apoptosis. Free Radic Biol Med. 2010; 49: 1925-36.

23. Jiang X, Chen C, Zhao W, Zhang Z. Sodium arsenite and arsenic trioxide differently affect the oxidative stress, genotoxicity and apoptosis in A549 cells: an implication for the paradoxical mechanism. Environ Toxicol Pharmacol. 2013; 36: 891-902.

24. McNeely SC, Taylor BF, States JC. Mitotic arrest-associated apoptosis induced by sodium arsenite in A375 melanoma cells is BUBR1-dependent. Toxicol Appl Pharmacol. 2008; 231: 61-7.

25. Guida E, Bisso A, Fenollar-Ferrer C, Napoli M, Anselmi C, Girardini JE, Carloni P, Del Sal G. Peptide aptamers targeting mutant p53 induce apoptosis in tumor cells. Cancer Res. 2008; 68: 6550-8.

26. Reichard JF, Motz GT, Puga A. Heme oxygenase-1 induction by NRF2 requires inactivation of the transcriptional repressor BACH1. Nucleic Acids Res. 2007; 35: 7074-86.

27. Chen W, Sun Z, Wang XJ, Jiang T, Huang Z, Fang D, Zhang DD. Direct interaction between Nrf2 and p21Cip1/WAF1 upregulates the Nrf2-mediated antioxidant response. Mol Cell. 2009; 34: 663-73.

28. Hussong M, Börno ST, Kerick M, Wunderlich A, Franz A, Sültmann H, Timmermann B, Lehrach H, HirschKauffmann M, Schweiger MR. The bromodomain protein BRD4 regulates the KEAP1/NRF2-dependent oxidative stress response. Cell Death Dis. 2014; 5: e1195.

29. Yang C, Tan YX, Yang GZ, Zhang J, Pan YF, Liu C, Fu J, Chen Y, Ding ZW, Dong LW, Wang HY. Gankyrin has an antioxidative role through the feedback regulation of $\mathrm{Nrf} 2$ in hepatocellular carcinoma. J Exp Med. 2016; 213: 859-75.

30. Zucker SN, Fink EE, Bagati A, Mannava S, BianchiSmiraglia A, Bogner PN, Wawrzyniak JA, Foley C, Leonova KI, Grimm MJ, Moparthy K, Ionov Y, Wang J, et al. Nrf2 amplifies oxidative stress via induction of Klf9. Mol Cell. 2014; 53: 916-28.

31. Gruosso T, Mieulet V, Cardon M, Bourachot B, Kieffer Y, Devun F, Dubois T, Dutreix M, Vincent-Salomon A, Miller KM, Mechta-Grigoriou F. Chronic oxidative stress promotes $\mathrm{H} 2 \mathrm{AX}$ protein degradation and enhances chemosensitivity in breast cancer patients. EMBO Mol Med. 2016; 8: e201505891.

32. Mahalingaiah PK, Singh KP. Chronic oxidative stress increases growth and tumorigenic potential of MCF-7 breast cancer cells. PLoS One. 2014; 9: e87371.

33. Balliet RM, Capparelli C, Guido C, Pestell TG, MartinezOutschoorn UE, Lin Z, Whitaker-Menezes D, Chiavarina B, 
Pestell RG, Howell A, Sotgia F, Lisanti MP. Mitochondrial oxidative stress in cancer-associated fibroblasts drives lactate production, promoting breast cancer tumor growth: understanding the aging and cancer connection. Cell Cycle. 2011; 10: 4065-73.

34. Toullec A, Gerald D, Despouy G, Bourachot B, Cardon M, Lefort S, Richardson M, Rigaill G, Parrini MC, Lucchesi C, Bellanger D, Stern MH, Dubois T, et al. Oxidative stress promotes myofibroblast differentiation and tumour spreading. EMBO Mol Med. 2010; 2: 211-30.

35. Chan JSK, Tan MJ, Sng MK, Teo Z, Phua T, Choo CC, Li L, Zhu P, Tan NS. Cancer-associated fibroblasts enact field cancerization by promoting extratumoral oxidative stress. Cell Death Dis. 2017; 8: e2562.

36. Bykov VJ, Zhang Q, Zhang M, Ceder S, Abrahmsen L, Wiman KG. Targeting of mutant p53 and the cellular redox balance by APR-246 as a strategy for efficient cancer therapy. Front Oncol. 2016; 6: 21.

37. Roder C, Thomson MJ. Auranofin: repurposing an old drug for a golden new age. Drugs R D. 2015; 15: 13-20.

38. Liu DS, Duong CP, Haupt S, Montgomery KG, House CM, Azar WJ, Pearson HB, Fisher OM, Read M, Guerra GR, Haupt Y, Cullinane C, Wiman KG, et al. Inhibiting the system $\mathrm{xC}$-/glutathione axis selectively targets cancers with mutant-p53 accumulation. Nat Commun. 2017; 8: 14844.

39. Wassman CD, Baronio R, Demir Ö, Wallentine BD, Chen CK, Hall LV, Salehi F, Lin DW, Chung BP, Hatfield GW, Richard Chamberlin A, Luecke H, Lathrop RH, et al. Computational identification of a transiently open $\mathrm{L} 1 / \mathrm{S} 3$ pocket for reactivation of mutant p53. Nat Commun. 2013; 4: 1407.

40. Gorrini C, Harris IS, Mak TW. Modulation of oxidative stress as an anticancer strategy. Nat Rev Drug Discov. 2013; 12: 931-47.

41. Panieri E, Santoro MM. ROS homeostasis and metabolism: a dangerous liason in cancer cells. Cell Death Dis. 2016; 7: e2253.

42. Lu J, Holmgren A. The thioredoxin antioxidant system. Free Radic Biol Med. 2014; 66: 75-87.

43. Bhatia M, McGrath KL, Di Trapani G, Charoentong P, Shah F, King MM, Clarke FM, Tonissen KF. The thioredoxin system in breast cancer cell invasion and migration. Redox Biol. 2016; 8: 68-78.

44. Kwon MY, Park E, Lee SJ, Chung SW. Heme oxygenase-1 accelerates erastin-induced ferroptotic cell death. Oncotarget. 2015; 6: 24393-403. https://doi.org/10.18632/ oncotarget. 5162 .
45. Lee HN, Jin HO, Park JA, Kim JH, Kim JY, Kim B, Kim W, Hong SE, Lee YH, Chang YH, Hong SI, Hong YJ, Park IC, et al. Heme oxygenase-1 determines the differential response of breast cancer and normal cells to piperlongumine. Mol Cells. 2015; 38: 327-35.

46. Piskounova E, Agathocleous M, Murphy MM, Hu Z, Huddlestun SE, Zhao Z, Leitch AM, Johnson TM, DeBerardinis RJ, Morrison SJ. Oxidative stress inhibits distant metastasis by human melanoma cells. Nature. 2015; 527: 186-91.

47. Le Gal K, Ibrahim MX, Wiel C, Sayin VI, Akula MK, Karlsson C, Dalin MG, Akyürek LM, Lindahl P, Nilsson J, Bergo MO. Antioxidants can increase melanoma metastasis in mice. Sci Transl Med. 2015; 7: 308re8.

48. Sayin VI, Ibrahim MX, Larsson E, Nilsson JA, Lindahl P, Bergo MO. Antioxidants accelerate lung cancer progression in mice. Sci Transl Med. 2014; 6: 221ra15.

49. Peng X, Zhang MQ, Conserva F, Hosny G, Selivanova G, Bykov VJ, Arnér ES, Wiman KG. APR-246/PRIMA-1MET inhibits thioredoxin reductase 1 and converts the enzyme to a dedicated NADPH oxidase. Cell Death Dis. 2013; 4: e881.

50. Kim NH, Park HJ, Oh MK, Kim IS. Antiproliferative effect of gold(I) compound auranofin through inhibition of STAT3 and telomerase activity in MDA-MB 231 human breast cancer cells. BMB Rep. 2013; 46: 59-64.

51. Peng H, Wang H, Xue P, Hou Y, Dong J, Zhou T, Qu W, Peng S, Li J, Carmichael PL, Nelson B, Clewell R, Zhang Q, et al. Suppression of NRF2-ARE activity sensitizes chemotherapeutic agent-induced cytotoxicity in human acute monocytic leukemia cells. Toxicol Appl Pharmacol. 2016; 292: 1-7.

52. Raninga PV, Di Trapani G, Vuckovic S, Bhatia M, Tonissen KF. Inhibition of thioredoxin 1 leads to apoptosis in drugresistant multiple myeloma. Oncotarget. 2015; 6: 15410-24. https://doi.org/10.18632/oncotarget.3795.

53. Györffy B, Lanczky A, Eklund AC, Denkert C, Budczies J, Li Q, Szallasi Z. An online survival analysis tool to rapidly assess the effect of 22,277 genes on breast cancer prognosis using microarray data of 1,809 patients. Breast Cancer Res Treat. 2010; 123: 725-31.

54. Campaner E, Rustighi A, Zannini A, Cristiani A, Piazza S, Ciani Y, Kalid O, Golan G, Baloglu E, Shacham S, Valsasina B, Cucchi U, Pippione AC, et al. A covalent PIN1 inhibitor selectively targets cancer cells by a dual mechanism of action. Nat Commun. 2017; 8: 15772. 